\title{
Close Looking and Conviction
}

\author{
Sam Rose \\ sper@st-andrews.ac.uk \\ University of St Andrews
}

This is a preprint of a paper that will appear in Art History.

\begin{abstract}
This article offers theoretical and practical reflections on the operations involved in description and interpretation based on 'close looking'. Explanations are given of the necessary appeal to contexts of origin or reception in order to disambiguate works of art, the widespread though rarely acknowledged reliance on an attenuated form of intention, and the way in practice that contexts are mobilised in the description or 'redescription' of works of art. Wider points made concern scepticism about the idea that works of art might determine their own interpretation (including problems with claims made as part of the phenomenological turn in image studies for the priority of direct or unmediated response to works of art), the quasi-allegorical nature of even ostensibly objectcentred interpretation, and consequences of the fact that modernism can function as a kind of context.
\end{abstract}

It is often said in relation to works of art that 'close looking' - or close attention to 'the object' - should have a privileged status. In the words of a recent Art Bulletin contributor: 'I never feel more like an art historian than when, after a student has done her share of exhaustive research, has tried to interpret an artwork in light of all the readings I have assigned, I ask her to set that aside. "Just look," I say. I ask her to base her observations on the way the artwork resists the context we can mobilize around it. Given what we know, what is different here from what we might expect?'1

This sort of thinking has had perhaps its most focused exploration in writing on modernism, where from Roger Fry through to Rosalind Krauss a critical tradition committed to close inspection of its objects, often called formalist or neo- 
formalist, has attempted to propose a method that minimises or cuts out entirely the appeal to external, contextual, or associative factors. According to one supporter of this tradition, Charles Harrison, the best justification for close attention to artworks is that certain works of art resulting from 'exceptional and intentional care' 'have a greater capacity than others to arbitrate what is and is not a valid description'. ${ }^{2}$ As such 'it is this capacity in the work to arbitrate its own description that the artist deserving of the name tests for in the self-critical procedures of the practice'. 'Harrison', a sympathetic commentator notes, 'claims that there is one point forcefully made by the writers of modernist criticism that deserves reiteration. That is that works of art are not necessarily interpretable by reference to social or historical events; they are events requiring interpretation in their own right'.4

In this essay I offer theoretical and practical reflections on the operations involved in description and interpretation based on close looking, a corollary of the account being scepticism about taking claims like Harrison's too literally. By 'claims like', as should become especially clear through the first and second sections, I include those made as part of the phenomenological turn in image studies for the priority of direct or unmediated response to works of art. ${ }^{5}$ Sections on 'Context and Disambiguation', 'The Appeal to Intention', and 'Description and Redescription', explore three main points. First, however close the inspection of a work of art, a context of origin or reception must be used in order to disambiguate it. Second, the typical and most secure form of disambiguation is not just an appeal to context of origin, but more narrowly to an attenuated form of intention. Third, description based on 'close looking' tends to operate via 'redescription' of picked out qualities according to a particular context or set of contexts (and in the case of 
much modernist criticism, that rather than a rejection of context, the writer's view of modernism itself functions as such a context). Finally I close with brief reflections on the way that a governing context, such as modernism, is used to attribute a generalised form of personhood to those artists to which it is applied.

In relation to writing on modernism, one notion that emerges is this: that this kind of writing might be understood as projecting onto a set of artists a universalized underlying intention to 'be modernist', then relativizing the interpretation of their works to a stylistic and ideological context based on the relevant stage in the particular writer's take on modernism and its unfolding. (This is not to deny that many writers on modernism are fully aware that 'minimising context' in the name of close looking really means a shift of the contextual burden on to their views of modernism and its art history; it is, though, to say that the subtleties of that position have often been lost on readers, explicators, and followers.)

More generally, interpretations based on 'just looking' (or on 'form', or 'structure', or the 'signifier'), emerge in practice as yielding not exactly a closer relation to the 'object', but a kind of allegory structured by whatever context is, however implicitly, being brought to bear. 'Modernist criticism' would then be one special form of this allegorisation, albeit an especially successful, influential, and according to some accounts defensible, one.

\section{Context and Disambiguation}

It is a familiar notion that pictures are deeply ambiguous. Art-historical examples range from simple decisions about representational matters much debated in the literature - is the item closest to us on the table in Parmigianino's Portrait of a 
Collector (in the National Gallery, London) a rat or an antique statue; are there faces hidden in Dürer's sketches of pillows (plate 1)? - to those 'monstrously ambiguous' works such as Giorgione’s Tempesta or Velasquez's Las Meninas, where ever-proliferating scholarship leads to ever-less hope of agreement about what exactly is going on. ${ }^{6}$

The issue can be presented in a radicalised manner through the idea of indiscernibles - of initially perceptually identical objects that when linked to different contexts yield dramatically different sets of properties. Take the short story by Jorge Luis Borges in which, in the early twentieth century, the character Pierre Menard produces a 'new' version of Don Quixote that is in fact identical word for word. ${ }^{7}$ In his text Borges is able to quote identical passages from the 'two' works and enumerate the striking differences between the earlier and later: the 'crude' becomes 'subtle'; the 'natural' becomes 'archaic' and 'affected'; the 'merely rhetorical' becomes 'brazenly pragmatic'. ${ }^{8}$ At one point it is said that 'The Cervantes text and the Menard text are verbally identical, but the second is almost infinitely richer'.$^{9}$ Inspired in part by this example, Arthur Danto's imaginary exhibition of seven identical looking painted and framed red rectangles has presented the pictorial equivalent most succinctly. Knowing that one of these is a painting of 'Israelites Crossing the Red Sea', that one is of 'Kierkegaard's Mood', one is a canvas primed by Giorgione on which a sacra conversazione was planned, and so on, leads to the realisation by the viewer that each of these initially indiscernible red squares has entirely different sets of properties, representing and expressing different things, or being something we may not acknowledge as a work of art at all. ${ }^{10}$ 
Leaving aside Danto's grander claims about the ontology of art, one lesson that has been drawn from this thought experiment is that fixing what a particular work of art is taken to be is a highly context-specific matter - a case of a text or sound structure or physical object being indicated in a particular context. ${ }^{11}$ Determination of the features of a work of art, including what it represents, expresses, means, and so forth, typically depends on an idea about the origin of that work. ${ }^{12}$ This determining origin can be roughly described as a 'context of origin', indicating a need for the information that the work was made by a particular person (or persons) at a particular time in a particular artistic context. More controversially, though undoubtedly often the case in practice, determination of the work can also depend on a 'context of reception', such as the particular gaze directed towards it or perspective from which it is looked at. ${ }^{13}$ Either way, use of such a context is the only way that ambiguity can be resolved. And because indiscernibles show that the features through which the work is disambiguated do not have to be immediately visually apparent, this means that works can in theory always be redescribed if a new construction of context of origin or reception is brought to bear. ${ }^{14}$

This adds up to what we know is the case from experience - that the works best able to arbitrate their own description are simply the ones about which we have the firmest agreement on the kinds of intention and context that fix their identity. The Tempesta has often been held up as a prime example of an inherently ambiguous paining. ${ }^{15}$ But a key reason that it is so ambiguous is that we have so have little information about the place and time and context of the painting's creation, including Giorgione's intentions, those of the patrons, and those of contemporary scholarly or lay audiences. Later but eminently non-modernist 
paintings like Luke Fildes' much-abused The Doctor are in fact far better able to arbitrate their own description (plate 2). But rather than a question of 'exceptional and intentional care' (Harrison), or the quality of pictorial thought, the reason that such a work does not yield deep ambiguity is that we are pretty sure that we know how Fildes and most significant contemporary audiences would have seen the work. Some of the most revered modernist works now edge close to the category of what James Elkins calls 'monstrous ambiguity', whereby the literature on them is so large that a whole term of a university course devoted to just one such work would be insufficient to cover it. ${ }^{16}$ The Doctor, on the other hand, is so 'stable' as a work that in art-critical and -historical articles it is only mentioned as an easy example rather than analysed as a problem, as if everything about it is eminently plain to see. It is more likely to be dealt with at length in medical journals than arthistorical ones, and there talked about as an emblem for the profession, or as evidence for historical medical practices. ${ }^{17}$

At this point it may be obvious to art historians familiar with critiques of 'context' that disambiguation via context of origin or reception means there are both horizontal and vertical paths to potentially unmanageable indeterminacy. ${ }^{18}$ In the first case the kind of information that may be included in the construction of 'originating context' has no easily definable limit to its outward extension. ${ }^{19}$ And in the second, the many conceivable reception-situations from the creation of the work right down to the present day mean a similarly open-ended proliferation of potentially determining 'contexts'.

As is understandable for an activity that claims to say historical things about its objects, art history has traditionally appealed to a version of originating context in order to establish the 'historically accurate' disambiguation of the work, 
and this in practice tends to reduce to a construction of the way that the original makers or users of the work would have seen or used the work. Many are happy to use 'intention' as a shorthand for this. But intention, as will be addressed further below, is an even more controversial term in art history than context. Whether acknowledging an embrace of intention or not, art historians have thus carefully worked up a set of vocabularies or rhetorical moves that allow them to circumvent this problem, in what I call the appeal to an attenuated form of intention. Something very like originating context or intentionality is regularly appealed to in order to disambiguate the work, but in a way that does not commit the writer to a belief in recoverable or conscious mental states determining the meaning of the work; talk of 'intention' is replaced by that of the posited 'purposefulness' that has constituted the 'forward-leaning look' of the object, by 'networks of forms of likeness' for the maker, or 'forms of likeness that things have in a particular form of life', by the vision, gaze, or not necessarily conscious experience of the maker, or even simply implied by the language of conscious artistic agency through which the interpretation is narrated. ${ }^{20}$

The unavoidability of some minimal notion of intention at this grounding level is demonstrated as clearly as anywhere in James Elkins' book on 'the origins of modern pictorial complexity', from which my opening examples were drawn. Elkins does not discuss or appeal directly to intention in deciding the cases of ambiguity, but in every instance the decision about what the picture is 'of' reduces to how its maker would have seen it, so that distinctions are drawn between (proper intentionally-grounded) 'seeing in' and (merely viewer-generated) 'reading in', with the latter described as 'projecting' or 'hallucinating'. ${ }^{21}$ To put the point another way: how many art history books, however radical in rhetoric, have 
ever treated their subject matter as a series of origin-less found objects, and thus discussed works of art without any reference to the usually attributed creator and date of creation? ${ }^{22}$

\section{The Appeal to Intention}

An important aspect of the claim that there is typically an appeal to an attenuated form of intention to establish the identity of the work - to purposefulness, or vision, or the gaze, or not-fully-conscious intentionality - is brought into focus by the case of modernist criticism. For while some, such as Harrison and Michael Fried, have stressed the importance of artistic intention, they have at the same time maintained that close inspection of the works in question is the privileged route to its discovery. ${ }^{23}$ And notoriously, other prominent writers on modernist art - including Clement Greenberg and Roger Fry - have allied their commitment to close looking with a more direct insistence that intention, at least at the conscious level found in artists' own statements about their work, is irrelevant to a proper understanding of the art in question. ${ }^{24}$ 'Formalists', as W. J. T. Mitchell has put it, 'think that meaning will take care of itself if we "subtract" extrinsic intention and let the language of the text work on us.'25

Nonetheless, as Mitchell's reference to 'extrinsic' intention implies, strategies like the formalist one that privilege the experience had in the face of the work leave open the possibility that meaning found in this way can be classed as a truer kind of ('intrinsic') intention. Amongst other places, the point is put especially directly in Stanley Cavell's insistence that the work alone should tell a properly capable observer everything they need about intention, and so that 'if we have earned the right to question it [about intention], the object will answer; otherwise 
not'. ${ }^{26}$ Whether the writer is Fry or Fried, then, this allows for an appeal to intention in order to establish the proper identity of the work, but with such intention found primarily 'in' the work through the critic's own 'close' inspection. The 'best possible' interpretation of the work is taken over and above the conscious statements of the artist, and is then narrated in a manner - with the artist activated by being made the subject of the sentence or clause - that presents the thought as well as the action described by the critic as the artist's own. ${ }^{27}$ Even where the relevance of intention is explicitly denied, the critic can nonetheless present the meaning they have discovered 'in' the work in strong terms of individual artistic agency.

The tactic is exemplified in Rosalind Krauss's essay 'The Latin Class', on Cy Twombly. ${ }^{28}$ There we read Krauss's arguments about Twombly's practice repeatedly narrated as if they indicate Twombly's intent, or in Krauss's words are 'crucial to getting Twombly's tone'. ${ }^{29}$ It is claimed, for example, that 'he drew his own conclusions about the import of Abstract Expressionist gesture'; that 'Twombly took up graffiti as a way of interpreting the meaning of action painting's mark'; that the connection with Jackson Pollock's work is 'a way of declaring how Pollock's work should be read, at least in Twombly's eyes'; that 'he cannot write "Virgil" on a painting and mean it straight'; and even of an interpretation contrary to Krauss's own that 'It is this reading Twombly seems to protest with every means at his disposal'. ${ }^{30}$ Then, revealing that Twombly's own written and spoken words seem to contradict her interpretation, Krauss turns to an apparently antiintentionalist stance: 
Do we care? To what degree do we have to respect Twombly's selfassessment [...] To what degree is it our responsibility to make an independent reading of an artist's work, acknowledging that while an artist may be a good interpreter of his or her own production, it does not follow that he or she will be its best one? No more than the analysand is the best reader of his or her dreams, motives, associations. To the contrary: The analysand is often the worst. ${ }^{31}$

What this hints at, while needing further elaboration, is the way that those advocates of modernist painting who are most apparently 'for' or 'against' intention, when arguing for the rightness of their own interpretation, in practice end up working according to the same basic principle. That is, the principle of the appeal to an attenuated form of intention - discovered primarily through close visual inspection - in order to disambiguate the work.

A way into the issue is offered by recent debates over intention and affect in the work of Henri Matisse, in particular as staged in a 2013 book by Todd Cronan, Against Affective Formalism. ${ }^{32}$ There Cronan takes aim at those he describes as 'affective formalists' among recent writers on Matisse, in particular: Gilles Deleuze; Yve-Alain Bois; Rosalind Krauss; J. M. Bernstein; Alastair Wright; Éric Alliez; and Jean-Claude Bonne. This mode of writing, for Cronan, is characterised throughout by the view that the artist developed a 'surefire "system" to produce violent sensations in the beholder's body', his works being 'affective "machines"' that directly transfer expressive content through their formal structure, thus obviating any kind of representational mediation. ${ }^{33}$ Instead, Cronan argues that: 
Matisse's work suggests something other than fantasies of expressive communion or affective transfer. Contrary to what Matisse sometimes said about the transparency of expression or the immediacy of affect [...] his works reflect on the problems of representing oneself to another, of how it is that a set of marks on a canvas or a sheet of paper can be understood or misunderstood, felt or rejected, by a beholder or even by oneself. Matisse came to feel that any work that did not open itself up to the possibility of failing to mean to another was a work that failed to mean at all [...] It is the discovery of the limits of and potentials for representation that is the primary content of his oeuvre'. ${ }^{34}$

Despite Matisse's nods to affect, Cronan concludes, his work 'is better seen as a profound reflection on the limits and powers of expression as a mode of understanding'. His work reveals 'that to express oneself to another requires an acknowledgement of the other's difference; this difference both threatens isolation and makes every connection like an unrepeatable gift.' To refuse this gift or to take it for granted - in the latter case to seek direct transmission of affects 'would involve a denial of the other and of oneself'. ${ }^{35}$

Foundational in the thought about Matisse that Cronan criticises, as he at one point notes, is the writing of Yve-Alain Bois. In the work that forms the crux of Bois's reading of Matisse's painting as 'blinding', he focuses in particular on the years between 1906 and 1911 during which Matisse 'conclusively put in place' his 'system', and in doing so definitively rejected the traditional conceptions of the decorative favoured by certain non-progressive contemporaries. ${ }^{36}$ As his patron's 
support waned in the face of Matisse's radicalism, Bois writes, Matisse 'took a huge gamble', and 'as if he had nothing to lose', carried 'to the extreme' the 'decorative profusion that had characterized many of his works from the previous years' ${ }^{37}$ Bois writes as follows of the two canvases that resulted:

Both Seville Still Life [c.1910-11, now in the State Hermitage Museum, St Petersburg] and Spanish Still Life [plate 3] are difficult to behold - that is, the viewer cannot gaze at their pullulating arabesques and color flashes for very long. As had already happened in Le Bonheur de vivre, but now much more so, these paintings appear to spin before the eye; nothing there ever seems to come to rest. Flowers, fruits, and pots pop up like bubbles that dissolve into their busy, swirling background as quickly as one manages to isolate them. The centrality of the figure is dismantled: the viewer feels compelled to look at everything at once, at the whole visual field, but at the same time feels forced to rely on peripheral vision to do so, at the expense of control over that very field. ${ }^{38}$

Following on from the earlier development of 'Matisse's system', this is what Bois calls Matisse's 'aesthetic of blinding'. ${ }^{39}$ It operates just as much, Bois writes, in an apparently simpler and calmer canvas such as Matisse's Music of 1910 (now in the State Hermitage Museum, St Petersburg), for there the sheer size of the picture 'one hundred-plus feet of saturated colour' - combines with the even distribution of figures to create an 'aporia of perception'.40 The pull of the background colour leaves one unable to contemplate a single musician, while converse attention to the picture as a whole is disrupted by the 'optical vibrations' of the vermillion 
forms against the blue-and-green ground. Bois bases his analyses on the notion that figure and ground are 'the very opposition on which human vision is based', and that the way they annul each other in Matisse's work - are 'deliberately destabilized' - means that 'our vision ends up blurred, blinded by excess'. ${ }^{41}$ This figure/ground aspect is not just blinding, but also hypnotising, 'based on a pendulum in our perception that makes us switch from our incapacity to focus on the figures to that of seizing the whole visual field at once, an oscillation that defines the very invention of Matisse's concept of the "decorative"'.42 To give just one more of Bois's analyses:

in Interior with Eggplants [plate 4] [...] everything cooperates in leading us astray: the pulsating repetition of the flower motif that invades floor and walls and blurs their demarcation; the reflection in the mirror that coloristically matches the landscape outside the window and confuses levels of reality; the syncopated rhythm and different scales of the ornamental fabrics; the gestures of the two sculptures (one on the table, the other on the mantelpiece) that rhyme with the arabesques of the folding screen. The three eggplants that give the painting its title are right in the middle of the canvas, but Matisse has blinded us to them and it is only through a conscious effort that we manage, only fleetingly, to locate them. ${ }^{43}$

So what is so wrong with this kind of writing? Cronan is committed to a view of intentionality roughly derived from that of Walter Benn Michaels and Stephen Knapp’s 1982 paper 'Against Theory', and re-presented a number of times over the years. ${ }^{44}$ According to this view, in order for us to interpret their meaning, 
works of art must be recognised as products of intention (which once discovered simply is their meaning). Refusing intention forces one to treat works as if they were objects like any other in the world rather than works of art made by a person or persons in a time and place, and leaves one able to appeal only to the subjective experience of the empirical viewer, which given its inherently personal nature is not something about which we can debate. At a number of points in his book Cronan makes clear that he equates the appeal to 'affect' with exactly this kind of experience of the empirical viewer. ${ }^{45}$ It is something that is within someone and simply a 'fact', that no one can reasonably confirm or deny - no one can tell you that you have failed to experience yourself correctly - and thus something no one can argue about. This investment of the picture-as-object alone with agency naturally obviates what the artist themselves did, thought, and felt, and has as a result, for Cronan, nothing at all to do with art and its interpretation.

Where Knapp and Michaels were reticent, Cronan offers a detailed and highly sophisticated view of intention, pointing out that those who refuse it tend to base their critique on an impossibly simplistic construct of what intent might involve. ${ }^{46}$ Perhaps most significantly, given the standard complaints about intention, Cronan claims his account to be 'antipsychological' in a sense, for it is 'not an appeal to artistic psychology, to figuring out what is going on inside an artist's head or heart'. ${ }^{47}$ Intention thus has nothing to do with a conscious mental plan in the mind that precedes the work - probably the most prevalent misrepresentation - nor is to be equated with the artist's conscious or articulated sense of the work's meaning. ${ }^{48}$ Instead it is a mixture of conscious and unconscious aspects, formed in and during the creation of the work. Intentions emerge 'in and through the process of production', and largely come to be known 
once they have been 'externalized for a beholder' (which can include the artist as beholder of their own picture). This beholder can in turn 'come to know him- or herself in the encounter with the work'. ${ }^{49}$

Analysis carried out on this basis is not a case of 'finally or ultimately knowing', of attaining a moment where 'the intention is fully captured or recovered by the interpreter'. ${ }^{50}$ It is instead simply 'to say that an artist meant something by his or her work, and that is what the art historian aims to understand by whatever means available' - recovery of past meanings is 'an ongoing challenge' that 'should not be forfeited on the grounds that one cannot have absolute certainty'. Its methodology is mixed, involving cautious usage of 'writings, statements, interviews, documents', and 'biography'. But the 'primary evidence' in the readings of Matisse 'are the visual characteristics of his work. And the characteristics that are relevant to my account are the ones I see as intended by the artist'. ${ }^{51}$

There are echoes of both Stanley Cavell and Richard Wollheim here, in the sense that intention is something that you can ultimately come to know through close inspection of the work itself, even in the most unlikely of cases. In Wollheim's account, close in many respects to Cronan's, the artist paints not just with the eyes, but for the eyes, at times acting as spectator of their own work, and imagining how a viewer of their work would respond. ${ }^{52}$ The effects of a work, in other words, are ones that the artist can be imagined to have experienced or intended themselves, as spectator of the work up until the moment it is done with. Thus Wollheim's famous multiple hour sessions of close inspection of single works would yield up apparently highly unlikely results which could be safely taken as definitely intended properties of the work, dispensing with any caution about 
visual ambiguity or overdetermination in the viewer's experience. ${ }^{53}$ Take his account of the realisation that Manet's paintings contained an internal spectator, where at the 1984 Manet exhibition at the Metropolitan Museum of Art 'time and time again, I discovered that I was engaging in imaginative enactments of a kind that might be expected to follow in the wake of my explicitly locating an internal spectator. Yet I had done no such thing. That being so, I trusted my eyes had not deceived me, and that the repertoire that I was following with such conviction was one for which my perception of the painting had given me some warrant: some implicit warrant, that is.' 54

This take on intention places the texts of Bois and others like him in a very different light. Recall their quasi-objective claims about the perceptual effects that Matisse's works have. If these were nothing more than 'affect' in Cronan's terms, they would not be universalizable, but instead would have to be described as differing for each individual viewer. Think also that what Bois describes (or at least Cronan represents him describing) as 'affects', simply could not be the result of a context-less object working on the nervous system of the viewer: the way that the 'thing' doing the affecting is described by these writers - by detailed reference to Matisse's biography and writings, and as the product of 'Matisse thought', or the 'Matisse system' - makes it painfully clear that it has already been preconstituted as 'a Matisse'. The object is securely disambiguated by the knowledge of its origins as a particular 'work' of art made by a particular artist in a cultural context, rather than just a found and context-less layer of oil and pigment.

What is happening here is that the effects are being described as the inevitable ones of looking at a Matisse, when seen as the particular cultural object that it is, created in a particular artistic context by a particular maker who would 
have seen it in a particular way. (Against the idea that affects are universal and inescapable, Bois and Wright note with evident disapproval that many have seen and still do see these works in ways that do not accord with their own readings, while Alliez and Bonn conclude that the logic of affect leaves viewers open to revel in their own responses, however personal.) ${ }^{55}$ The writers reject conscious and naïve constructs of intention. And in doing so they fall back on a mid way construct which they may or may not call 'intention' in theory, but which in practice leads them to work in a way that is importantly close to that of Cronan. ${ }^{56}$ Bois's idea that the perceptual effects described are so fundamental is gained from a combination of biographical and written evidence from Matisse himself, and the overriding sense in front of the work that these are the right experiences to have. ${ }^{57}$ Implicit in that judgement, of course, is that those are the experiences Matisse would have had of the work. As Bois says elsewhere, 'Matisse's goal was not to represent the thing, but to represent the effect of the thing on him when he was painting it, and to create the same effect on the beholder'.58

Some call it intentionality and others anti-intentionality, then. But the tactic of depsychologized intention-as-hypothetical-construct, where a cautious approach is taken to biography and conscious statements, and the effects of the work are given priority, is in fact a shared feature of the writing of Cronan and Bois. Their disagreement - and whatever Cronan says about not being able to argue with Bois, he certainly does - is about the particular effects that the work has, the underlying intentions in the work that these reflect, and the way that meaning should be constructed out of them. Disagreement, in other words, about how the work should be disambiguated -properly seen and experienced -based on how its originating context is understood. 


\section{Description and Redescription}

So much for intention. ${ }^{59}$ But what of the more general ideas of 'context' - whether original art-historical or cultural context, or later contexts of reception - of which intention is only really one component? I said earlier that one lesson of indiscernibles was that no matter what the immediately visible look of the work, the bringing to bear of a new context would always allow the work to be redescribed. If the features are not directly visible, the language of art writing is well equipped to redescribe them in a metaphorical or analogical way, a process that has been explained by various writers as one that is carried out by adopting a mode of (metaphorical) seeing-as (rather than seeing-in), by attention to nonvisible likenesses (rather than visible ones), or by the application of artistic perception (as opposed to pictorial perception). ${ }^{60}$ What I want to show in this section is not what underlies 'redescription', however, but rather how this works in practice: the way that the introduction of a context can then allow the art writer to redescribe properties of the work in the service of a general description or interpretation, perhaps especially when that description is based on 'close looking' ${ }^{61}$

An important side note to this is how such broadened contexts are subsequently recouped at the level of attenuated intention, as if the artist themselves would in some way have seen or experienced or 'meant' the work in the way that the redescription discovers. This is something like a rhetorical concertina effect, as the writing expands outwards to propose an increasingly inclusive set of contexts relative to which the work is to be described, then retracts back to imply that the description and meaning generated were all along a 
function of the (far more secure) intention and origin that make the work of art what it really 'is'. ${ }^{62}$

The process at work here can be seen in a recent article, 'The Power of Looking: Teaching Students the Value of Deceleration and Immersive Attention', based on a lecture given at the Harvard Initiative for Learning and Teaching conference in $2013 .{ }^{63}$ As the subtitle suggests, the author, Jennifer L. Roberts, sets out to illustrate the value of focused attention to works of art, of slowing down, of 'delay'. She approvingly quotes David Joselit's suggestion that paintings are 'time batteries, deep reservoirs of experience', and describes the great value her students have found in the exercise in which she sends them to look at a single painting for three hours while taking notes on it. To illustrate the point, she relates that she carried out the exercise herself on John Singleton Copley's Boy with a Squirrel (plate 5) as part of her research on a recent book, and that 'it took me a long time to see some of the key details that eventually became central to my interpretation and my published work on the painting'.

The unusual clarity of the account, given its origins in a didactic setting, allows for the abstraction of a basic recipe for putting together an interpretation grounded in close looking. Roberts's interpretation proceeds from picking out pictorial details like the fingers spanning the water glass, to giving information about Copley's having produced the painting to send to England. It then moves to a higher-level reading of the symbolising of, and allusion to, questions of time and distance the described details involve, before suggesting an overall meaning for the painting as being 'about its own patient passage through time and space'. The four general stages, which in practice can be carried out in a different order, and 
with different stresses, often so that one or other will only ever be implicitly dealt with, are: qualities; context; redescription; meaning.

1) Qualities. Pick out a selection of qualities of the object that appear significant.

1b) Purposefulness. Attribute some kind of purposefulness to them (treating them as the product of an agent acting, from which we can make inferences about that action).

2) Context. Bring in, allude to, or have already implicitly established, a context (which can be anything from the kinds of socio-historical background most often associated with the word, to an abstract concept, a methodology, a later context of reception, or a general proposition about meaning in artworks of a particular type).

3) Redescription. Redescribe the qualities originally picked out in terms relevant to the context (through metaphor, metonym, synecdoche, and association to other works or things).

4) Meaning. Narrate the redescribed qualities to give a 'meaning' of the work.

This works in the example of Copley's painting as follows:

1) Qualities are picked out. 
- After nine minutes it was noticed 'that the shape of the boy's ear precisely echoes that of the ruff along the squirrel's belly'.

- After 21 minutes Roberts 'registered the fact that the fingers holding the chain exactly span the diameter of the water glass beneath them'.

- After 45 minutes she 'realized that the seemingly random folds and wrinkles in the background curtain are actually perfect copies of the shapes of the boy's ear and eye'.

1b) Purposefulness is attributed to the qualities.

- Along with the echo of boy's ear and squirrel's belly it was noticed that 'Copley was making some kind of connection between the animal and the human body and the sensory capacities of each'.

- The echo of background curtain and boy's ear and eye are 'as if Copley had imagined those sensory organs distributing or imprinting themselves on the surface behind him'.

(In both cases here note the artist as subject of the sentence or clause: 'Copley was making'; 'as if Copley had imagined'.)

2) A context is established, based on details of Copley's slow, long-distance relationship with the London art world.

- Copley was already successful in the United States but was keen to get feedback from the London art world.

- He created and sent this picture to begin the correspondence. 
- It was around eleven months before a letter was received in reply, informing him of the reception, and future correspondence continued at a similar pace.

3) The qualities picked out in the initial close looking are redescribed in terms relevant to the context.

- The squirrel is a flying squirrel, as the belly indicates, 'a species native to North America with obvious thematic resonances for the theme of travel and movement', while 'squirrels in painting and literature were commonly understood to be emblems of diligence and patience'.

- The glass of water and hand 'evokes the passage of a sensory chain across a body of water and thereby presents in microcosm the plight or task of the painting itself'.

- The profile format, 'in the eighteenth century [...] was very strongly associated with persistence in time and space.' Profiles were usually seen on coins, and ' $\mathrm{i}] \mathrm{n}$ essence, a coin is a tool for transmitting value through space and time in the most stable possible way. Coins are technologies for spanning time and distance, and Copley borrows from these associations for a painting that attempts to do the same thing.'

4) The redescribed qualities are brought together to support a meaning.

- 'The painting is about its own patient passage through time and space [...] Copley's painting, in other words, is an embodiment of the delays that it was created to endure.' 
This is a clear illustration of the process whereby contexts are expanded outwards to enrich the reading of the work - from the moment of creation of the work, to Copley's artistic context, to the London art world and transatlantic dialogue, and the reception of Copley's work there - which is then secured as quasi-intentional. (In the more complex presentations that are usual in academic art-historical writing, the process seen here may be carried out a number of times, as a series of loops are made that select qualities, explicate a context, redescribe the qualities, select new qualities, and so on.) ${ }^{64}$ An opening suggestion that details picked out were later crucial to the interpretation does briefly imply a view of 'found' details and 'made' interpretation, but Roberts' text is predominantly couched in the language of recovery of historical meaning. While she is cautious and subtle in her claims, the interpretation is naturally to be taken as an historically-grounded one - the meanings, associations, and such like that she suggests to her audience, are all also meant as if for Copley in the past, such that he may well at some level have seen or experienced the painting as, post-interpretation, we now should.

To some formalist or modernist critics the analysis in question might be rejected as a classic example of socio-historical or culturological contextual interpretation. Meaning, it might be claimed, is being made by drawing on a context brought from 'outside'. But this would entirely miss the point that there is no question of secure visual analysis without some idea of a context of origin or reception that will decide what the work really 'is'. In this sense we are always dealing with preferred forms of what might constitute a disambiguating context, rather than any neatly internal/external, text/context, situation.

This can be seen in another, briefer, example, taken from a critic of exactly this kind of interpretation - who writes that 'as important as these contextual 
analyses can be, in them the task of interpreting the meaning of the work itself often yields to accounting for its causes. The work of art is treated as a result of certain pressures, an effect of its context's causing'. ${ }^{65}$ Dealing with Jackson Pollock, the art historian, Michael Schreyach, follows a similar line to Cronan in resisting the reduction of meaning to either causal explanations (including explicit artistic statements) or the affective responses of an empirical viewer. Instead his argument for an 'intentionalist position' is more or less identical to Cronan's. He adds explicit nods to Wollheim and Charles Harrison, an acknowledgement of the 'hypothetical' nature of his construction of intention, and a by now familiar appeal to the perceptual effects of the work of art as the best way to get at intention.

Putting Schreyach's interpretation of Pollock's Number 1, 1949 (plate 6) into the schema outlined above, the first stage proceeds as usual:

1) Qualities are picked out, as a set of perceptual effects are described $a s$ qualities possessed by the work.

- It is difficult for a viewer to select from the surface any single pictorial incident that seems to impinge upon attention more than any other.

- But with the gaze fixed at the centre, a relatively stable elliptical area appears, which counters the all-over quality of the surface.

1b) Purposefulness is established.

- 'This thwarting of visual equilibrium has implications for how we interpret the modes of experience or consciousness Pollock wants to express.' 
Something more interesting happens, however, at the stage of adding context, for the writing moves directly from initially picked out qualities to a higher-level redescription of those aspects of the work. What is easily missed here is what has already been set up by the lengthy earlier part of the essay, as well as a footnote to Michael Fried's 'Shape as Form' essay (one of the set of mid- to late-1960s texts that were foundational in the development of Fried's ideas about modernist painting). ${ }^{66}$ This indicates that:

2) the 'context' added by allusion is one of a particular view of modernist painting and the kind of interpretation proper to it, deriving primarily from Fried and to a lesser extent Walter Benn Michaels and others. It involves two propositions crucial to what follows.

- One of the features of high modernist painting was its resistance to the literal shape of its material support, so that the painting operates as a work of art, rather than like any other object in the world.

- The work of art - having successfully avoided reduction to mere object - is the product of an intention, and the dramatizing of its intentionality is one significant feature of modernist painting.

3) The qualities of the work (the particular perceptual effects highlighted) are redescribed in accordance with the context.

- 'the internal framing of the ovoid provides a certain emergent structure to the image which restores to the painting a degree of pictorial cohesiveness that is more or less independent of both its perceived limits and the literal frame, as if the pictorial structure is now understood to be generated from 
the inside out, from the interior of the image to its frame, rather than the other way around, and creates a sense of the painting as a whole.'

- 'the constitution of that totality - a structure that serves as a medium for expressive content, versus a merely literal shape - is to be understood itself as emergent from the figurative depth of the field, not given beforehand' - 'The total visual field then, far from being an accumulation of marks that are taken as traces or indexes of [Pollock's] movements or actions above the canvas, can be understood to be expressive of something like the subject's emergence to the world, and of the freedom of his or her creative intentionality.'

4) A meaning is provided.

- 'On this account, Number 1, 1949 conveys something about the conditions of experience through which a reflective subject might grasp the significance of her embodied modes of intentionality - her own deep animating intentions.'

In both of these cases, whether description is through openly socio-historical interpretation or adopts an avowedly modernist and anti-contextual stance, the same basic structure is in operation. A small set of qualities are picked out and redescribed at a new level in accordance with a set of contexts, and attenuated intentionality is retrospectively recovered to secure the reading as an historical one. In the latter example the particular construction of what modernism as an artistic enterprise involved itself comes to function as a context. ${ }^{67}$ 


\section{Describing Objects/Making Modernists}

Where does this all leave things? The account that I have offered is based on two main points:

1) Intention of an attenuated kind is typically appealed to in order to establish what a work is, and so the way it should be seen.

2) 'Close looking' in practice operates via 'redescription' - picking out qualities and redescribing them in terms of a context - and this tends to be folded back into the appeal to an attenuated form of intention. (Rather than standing for a disavowal of context, in this case, modernism itself can function as such a context.)

In closing, I would like to highlight something further that is brought into focus by the account of close looking offered here. Applying the analysis and the two points above to writing on modernism adds up to a further point:

3) That a governing context brought to bear, such as modernism, functions in art writing to attribute a generalised form of intentionality to the set of artists to which it is said to be relevant.

It is uncontroversial to say that the greatest modernist critics have been those with the most convincing and passionately defended constructions of what 'modernism' as a whole involves - a fact declared by the modernism-centred rather than work- or artist-specific nature of some of the most violent debates 
between them: 'A View of Modernism'; 'Using Language to do Business as Usual'; 'Clement Greenberg's Theory of Art'; 'How Modernism Works'. ${ }^{68}$ Often it has been pointed out, too, that this results in 'modernism' for these writers becoming a separate volitional entity with its own intentional force. 69

What is less clear, though, is the extent to which constructions of modernism are then mobilised as a context, and used to construct ideas of artistic purposefulness. This is no more than the necessary consequence of embracing the circularity that results from the pattern of intention-inference in play. The works that the understanding, committed, and true to their own response writer singles out are those works that compel conviction. ${ }^{70}$ In turn, the writer knows that, due to their 'internal' take on intention, what they feel is there in the work is all they need in order to decide what was meant by it. ('If we have earned the right to question it, the object itself will answer; otherwise not'.) The works are thus said to compel conviction because they are intentionally made to participate in the (modernist) tradition of artmaking favoured by the writer: they are described as if the artist intended their work to engage (in whatever way the critic deems suitable) with those works of the recent past that also (for the writer) compelled conviction. Close looking will of course play its part at this stage. But everything significant about the work's identity and the kind of attention that should govern its description has already been decided by the certainty that the artist set out to work in the given modernist tradition. Here is Rosalind Krauss on one of those artists she sees as the 'Knights of the Medium' providing the necessary continuation of modernism into the present day: 'I think what I'm more interested in is stumbling on work that for one reason or another I recognise as genuine and then I try to understand where it comes from and what it is that secures the 
notion of it as authentic [...] I believed that the work of the Irish artist James Coleman is the real thing when I saw it. Outraged people weren't saying 'fake and phoney', but the critical arguments for the work were themselves, I felt, fake and phoney. The defence of the work was made on grounds that I thought were irrelevant to the interest of the work. The grounds were national identity, the construction of identity, all this constructionalist stuff, which I thought had nothing to do with the work. What had to do with the work was the fact that he had essentially invented a medium. He invented a medium as the technical support for the work.'71

In regard to contemporary art, this means that impressively close attention to works leads to Fried and Krauss defending their own narratives of the continuation of modernism by their own carefully picked sets of artists: the problematic of beholding (of absorption, theatricality, and the 'dialectically transformed [...] high modernist ideal of "presentness"') in the work of Anri Sala, Charles Ray, Joseph Marioni, Douglas Gordon, and a range of photographers; ${ }^{72}$ or the reconstitution of modernism's self-reflexive medium-based practice and its connected autonomy via the idea of 'technical support', with Ed Ruscha, William Kentridge, Sophie Calle, Harun Farocki, Christian Marclay, and James Coleman cast as 'those very few artists who have had the courage to resist the aneurystic purge of the visual, a purge meant to bury the practice of specific mediums under the opprobrium of a mindless moralizing against the grounds of art itself'. ${ }^{73}$

With high modernism, the closest most careful attention to those stillcanonical works yields the figure we commonsensically think of as one artist setting out to make aesthetic equivalents for their experiences, pursuing the logic of reduction to the essence of the specific medium, blinding or hypnotizing the 
contemporary viewer, struggling with the possibility of representing oneself to another, and so on. Found through close looking, the individual agents-asmodernist-artists designated under each proper name ('Matisse') are made to proliferate in step with that of modernisms, while within each individual writer's modernism we find a likeness in the personhood and the work of all included figures, as their deep goals and the qualities of their work alike are redescribed at the higher level of participation in that particular narrative of modernism's history.

For this reason, Harrison's suggestion - that the artist deserving of the name tests for their work's capacity to 'arbitrate its own description' - gets things the wrong way round. In practice, art writers find works that compel conviction then carefully redescribe them, making their own kind of modernists out of the people who created them.

Notes

This essay was prompted by ideas from Gavin Parkinson, Christopher Green, and Polly Mitchell. Particular thanks also go to Bence Nanay, Martin Golding, Whitney Davis, and Lily Foster for extended discussion, and to Ed Wouk, Sophie Martin, Justin Underhill, Ünver Rüstem, Sarah Kennedy, Karen Collis, Claire White, Paul Binski, Lizzie Mitchell, and the anonymous Art History reviewers for helpful comments. Research for this essay was supported by: the Arts and Humanities Research Council; the Courtauld Institute of Art; and Peterhouse, Cambridge.

\footnotetext{
${ }^{1}$ Rebecca Zorach, 'Notes from the Field', Art Bulletin, 94, December 2012, 489.

${ }^{2}$ Charles Harrison, Essays on Art and Language, second edition, Cambridge, 2001 (first published 1991), xxi.
} 


\footnotetext{
${ }^{3}$ Harrison, Essays on Art and Language, xxii.
}

${ }^{4}$ Stephen Moonie, 'Charles Harrison, Since 1950', Rebus, Autumn/Winter 2009, http://www.essex.ac.uk/arthistory/research/rebus.aspx.

${ }^{5}$ For recent skeptical art historical takes on description, though without my analytic framework, see James Elkins, On Pictures and the Words that Fail Them, Cambridge, 1998; Dario Gamboni, Potential Images: Ambiguity and Indeterminacy in Modern Art, London, 2002; A.A. Donohue, Greek Sculpture and the Problem of Description, Cambridge, 2005; Jas' Elsner, 'Art History as Ekphrasis', Art History, 33, February 2010, 10-27. Closer in approach, though not focused on description as such, is Whitney Davis, A General Theory of Visual Culture, Princeton, 2011. On the phenomenological turn, see also the end of section 1 , and footnote 22 below.

${ }^{6}$ The phrase, and these examples, are drawn from the most sustained meditation on the subject, James Elkins's Why Are Our Pictures Puzzles? On the Origins of Modern Pictorial Complexity, New York, 1999.

${ }^{7}$ Jorge Luis Borges, 'Pierre Menard: Author of the Quixote' [1941], Fictions, trans. Andrew Hurley, London, 2000, 33-43.

${ }^{8}$ Borges, 'Pierre Menard', 39-41.

${ }^{9}$ Borges, 'Pierre Menard', 40.

${ }^{10}$ Arthur Danto, The Transfiguration of the Commonplace, New York, 1981, 1-32, as first explored in Arthur Danto, 'The Artworld', Journal of Philosophy, 61, October 1964, 571-584. The other foundational text in this regard, arguing that the properties of the work will depend on the particular category that it is approached under, is Kendall Walton, 'Categories of Art', Philosophical Review, 79, July 1970, 334-367.

${ }^{11}$ See especially Jerrold Levinson, 'What a Musical Work Is', Journal of Philosophy, 77, January 1980, 5-28; reprinted in Jerrold Levinson, Music, Art, and Metaphysics: Essays in Philosophical Aesthetics, Ithaca, New York, 1990, 63-88 (and for a late reiteration and summary, Jerrold Levinson, 'Aesthetic Contextualism', Postgraduate Journal of Aesthetics, 4, Winter 2007, 1-12); and Peter Lamarque, Work and Object: Explorations in the Metaphysics of Art, Oxford, 2010. According to Danto's notion of 'indiscernible counterparts', any thing that is a work of art might have an indiscernible counterpart that is a 'mere real thing', and as such it must be an 'air of theory' that gives its identity qua artwork. I should stress that Danto put the notion to use as part of a particular theory of what art is, which I have no need to 
either endorse or reject here. Whether or not Danto's ontology holds, the simpler lesson for description is that any work can be treated as an indiscernible counterpart when the 'is' of artistic identification is given differently: however it looks, its attributed properties are likely to change radically if its backstory is changed. On Danto's use of indiscernibles, see J. A. Fisher, 'Is There a Problem of Indiscernible Counterparts', Journal of Philosophy, 92, September 1995, 467-484, and for an earlier application to art history, David Carrier, Artwriting, Amherst, 1987. On the phenomenology of indiscernibles, see the article in note 14 below.

12 That is to say, in Lamarque's terms, the relational or Intentional properties or 'social facts' that attach to the cultural 'work', rather than the physical properties that attach to the base 'object'; see Lamarque, 'Work and Object', in Work and Object, 4-6, 56-77.

${ }^{13}$ Disputing and extending the work of Jerrold Levinson, a technical discussion of this possibility, tied to the even stronger claim of 'individuation' (that the work given a new context of origin or reception is not only seen or heard or experienced a different way, but is in fact a different work altogether), is given in Carl Matheson and Ben Caplan, 'Fine Individuation', British Journal of Aesthetics, 47, April 2007, 113137. This point is fundamental to such revisionist art historical theorizing as Mieke Bal and Norman Bryson, 'Semiotics and Art History', Art Bulletin, 73, 1991, 174-208.

${ }^{14}$ The relevant process of 'redescription' is outlined in section 3 below. For more on this point (including the argument that, contra one common reading of Danto, this redescription will change the experience had in the face of the work), see Bence Nanay, 'Cognitive Penetration and the Gallery of Indiscernibles', Frontiers in Psychology, 5, 2014, 1527. doi: 10.3389/fpsyg.2014.01527, and Davis, A General Theory of Visual Culture, 277-321.

${ }^{15}$ Elkins, Why Are Our Pictures Puzzles?, 130-141.

${ }^{16}$ Listing examples of such works in the 1990s, Elkins proposed the Brancacci Chapel, the Mona Lisa, Las Meninas, the School of Athens, the Oath of the Horatii, the Tempesta, the Primavera, and the Sistine Ceiling, with 'borderline' cases' (having large but still masterable literatures) given as the Arena Chapel, the Burial of Count Orgaz, the Isenheim Altarpiece, the Demoiselles d'Avignon, Vermeer's Art of Painting, and the Garden of Earthly Delights; Elkins, Why Are Our Pictures Puzzles?, 123-124.

${ }^{17}$ Compare the treatments in Stella Tillyard, "The End of Victorian Art'?: W.R. Sickert and the Defence of Illustrative Painting', in Brian Allen, ed., Towards a Modern Art World, New Haven, 1995; Jane 
Moore, 'What Sir Luke Fildes' 1887 Painting The Doctor Can Teach Us About the Practice of Medicine Today’, British Journal of General Practice, 58, March 2008, 210-213.

${ }^{18}$ The classic art historical discussions are Bal and Bryson, 'Semiotics and Art History'; and Norman Bryson, 'Art in Context', in Ralph Cohen, ed., Studies in Historical Change, Charlottesville, 1992, 1842. (Bryson's use of Derrida is especially relevant here: 'At least two principles are at work: the contextual determination of meaning, and the infinite extendability of context. Derrida: "This is my starting point: no meaning can be determined out of context, but no context permits saturation."'; 'Art in Context', 39.) For a recent summary and discussion of scholarship on the problems with historical context, see Martin Jay, 'Historical Explanation and the Event: Reflections on the Limits of Contextualization', New Literary History, 42, Autumn 2011, 557-571.

${ }^{19}$ Jerrold Levinson's adumbration of 'musico-historical context' is sufficiently telling: ' I will not attempt to give a strict definition of musico-historical context, but will confine myself to pointing out a large part of what is involved in it. The total musico-historical context of a composer $P$ at a time $t$ can be said to include at least the following: (a) the whole of cultural, social, and political history prior to $t$, (b) the whole of musical development up to $t$, (c) musical styles prevalent at $t$, (d) dominant musical influences at $t$, (e) musical activities of $P$ 's contemporaries at $t$, (f) $P$ 's apparent style at $t$, (g) $P$ 's musical repertoire at $t$, (h) $P$ 's oeuvre at $t$, (i) musical influences operating on $P$ at $t$ '; Levinson, 'What a Musical Work Is', 10-11.

${ }^{20}$ For these examples see Michael Baxandall, Patterns of Intention, New Haven, 1985; Davis, A General Theory of Visual Culture; Emmanuel Alloa, 'Seeing-as, seeing-in, seeing-with. Looking through Images', in Elisabeth Nemeth et al., ed., Image and Imaging in Philosophy, Science and the Arts, Frankfurt, 2011, 179-190.

${ }^{21}$ Elkins, Why Are Our Pictures Puzzles?, especially 120, 180, 215-216, 220-221, 241.

${ }^{22}$ A point made more generally in Noël Carroll, 'Anglo-American Aesthetics and the Hermeneutics of Suspicion', in Beyond Aesthetics: Philosophical Essays, Cambridge, 2001, 180-190. This raises the issue of the extent to which the phenomenological turn in image studies - seen in appeals to presence, affect, animation, and so forth - might escape this subservience to constructions of particular art histories. (For a recent polemical discussion, see Keith Moxey, Visual Time: The Image in History, Durham, 2013, and for a methodologically distinct form of the argument, David Freedberg, 'Memory in Art: History and the Neuroscience of Response', in Suzanne Nalbantian, Paul M. Matthews, James L. McClelland, eds., The 
Memory Process: Neuroscientific and Humanistic Perspectives, Cambridge, Mass., 2011.) This and the following sections aim to indicate how and why in practice originating context still typically (and perhaps necessarily) functions as a constraint in such writing. In short, the point is that the preconstitution of the work (via context of origin or similar) means that the 'effects' described will be those of seeing the work of art when taken to be the particular cultural object that it is thought to be.

${ }^{23}$ For Fried on intention, see Michael Fried, Four Honest Outlaws: Sala, Ray, Marioni, Gordon, New Haven, 2011, 15, and more generally Fried, 'An Introduction to my Art Criticism', in Art and Objecthood: Essays and Reviews, Chicago, 1998, 49-52.

${ }^{24}$ The obvious exceptions here are Michael Fried and Charles Harrison, as I bring out below.

${ }^{25}$ W.J.T. Mitchell,, ed., Against Theory: Literary Studies and the New Pragmatism, Chicago, 1985, 5.

${ }^{26}$ Stanley Cavell, Must We Mean What We Say? A Book of Essays, Cambridge, 2002 (first edition 1967), 237.

${ }^{27}$ This accords with what has elsewhere been described as a 'hypothetical' view of intention. Applied to literary texts, this is the view that rather than either (conscious) 'utterer's meaning' or (formal) 'sentence meaning', the proper object of critical attention is the hypothetical reconstruction of 'utterance meaning', or the intended meaning that the particular text would have been likely to have had in the original context in which it was made, whether or not the creator consciously intended it to do so or not. For a general articulation, see Jerrold Levinson, 'Hypothetical Intentionalism: Statement, Objections, and Replies', in Contemplating Art, Oxford, 2006. As its antipsychologistic stance means that Hypothetical Intentionalism rejects the usage of private avowals of artistic intention such as artists' letters, this leaves open the question of whether the critics discussed here can at the same time claim to avoid psychologizing and help themselves to such private statements. The ultimate coherence of the critical strategy, and its potential drift into something more like 'modest actual mentalism', is something I do not address here.

${ }^{28}$ Rosalind Krauss, 'The Latin Class' [1994], in Perpetual Inventory, Cambridge, Mass., 2010, 193-203.

${ }^{29}$ Krauss, 'The Latin Class', 202.

${ }^{30}$ Krauss, 'The Latin Class', 200-202.

${ }^{31}$ Krauss, 'The Latin Class', 203.

32 Todd Cronan, Against Affective Formalism: Matisse, Bergson, Modernism, Minneapolis, 2013. I take Cronan's book, and in particular the debate discussed here, to be representative of concerns shared by the 
group formed around nonsite.org who have recently attempted to give intellectual and critical weight to a revived form of modernism. Aside from Cronan, scholars involved include Michael Fried, Robert Pippin, Walter Benn Michaels, Charles Palermo, Lisa Siraganian, Jennifer Ashton and Michael Schreyach. For a sense of how, nonetheless, there is no standard view among contributors, as well as more on Cronan's takes on intention and so-called 'October aesthetics', see Todd Cronan et al., 'Against Affective Formalism: Matisse, Bergson, Modernism', nonsite.org 16 (June 2015). See also below, where a recent article by Schreyach is discussed.

${ }^{33}$ Cronan, Against Affective Formalism, 2-3.

${ }^{34}$ Cronan, Against Affective Formalism, 2.

${ }^{35}$ Cronan, Against Affective Formalism, 220.

${ }^{36}$ The canonical texts here are arguably Yve-Alain Bois, 'Matisse and "Arche-drawing", in Painting as Model, Cambridge, MA., 1990, 3-63, and Yve-Alain Bois, 'On Matisse: The Blinding', October, 68, Spring 1994, 60-121. For the most direct extension of this kind of thinking see Alastair Wright, Matisse and the Subject of Modernism, Princeton, 2004. For other especially prominent uses of affect in Matisse criticism see: Éric Alliez and Jean-Claude Bonne, La Pensée Matisse: Portrait de L'Artiste en Hyperfauve, Paris, 2005; J.M. Bernstein, 'In Praise of Pure Violence (Matisse's War)', in Diarmuid Costello and Dominic Willsdon, ed., The Life and Death of Images: Ethics and Aesthetics, London, 2008, 37-55. For the sake of concision, quotations here are drawn from Bois's most condensed accounts of Matisse's work, in Hal Foster et al, Art Since 1900: Modernism, AntiModernism, Postmodernism, London, 2012 (first edition 2004), 70-77, 100-105.

${ }^{37}$ Bois, in Art Since 1900, 100.

${ }^{38}$ Bois, in Art Since 1900, 101.

${ }^{39}$ Bois, in Art Since 1900, 74, 101. The development of Matisse's system in the first half of the decade is described in Bois, 'Matisse and "Arche-drawing".

${ }^{40}$ For the extended analysis of this canvas, see Bois, 'On Matisse: The Blinding', 109-114

${ }^{41}$ Bois, in Art Since 1900, 101.

${ }^{42}$ Bois, in Art Since 1900, 104.

${ }^{43}$ Bois, in Art Since 1900, 105.

${ }^{44}$ For the essay, critical responses, and restatement, see Mitchell, Against Theory. The influence of Knapp and Michaels is mostly implicit, but see Cronan's acknowledgement of the importance of both 
Michaels and Fried in Against Affective Formalism, 253. (In one section of The Shape of the Signifier, a book read and evidently approved of by Fried prior to publication, Michaels equates the 'Against Theory' thesis with Fried's 1967 'Art and Objecthood' essay, such that Fried's art/objecthood distinction accords with Michaels' intentional artwork/natural object distinction; Walter Benn Michaels, The Shape of the Signifier: 1967 to the End of History, Princeton, 2004, 82ff.)

45 The main work here is arguably done in the chapter 'Painting as Affect Machine', in Against Affective Formalism, 23-64, but see also the short summary statements on pages 10, 15, 17, 96-97, and 108 .

${ }^{46}$ For the terms of this reticence, see Henry Staten, 'The Shape of the Signifier: 1967 to the End of History', Modernism/Modernity, 12, April 2005, 363-364. Though the ideas are developed throughout the book, for Cronan's summary statement on intention see Against Affective Formalism, 10-14.

${ }^{47}$ Cronan, Against Affective Formalism, 12.

${ }^{48}$ Cronan, Against Affective Formalism, 12.

${ }^{49}$ Cronan, Against Affective Formalism, 13.

${ }^{50}$ Cronan, Against Affective Formalism, 14.

${ }^{51}$ Cronan, Against Affective Formalism, 12.

${ }^{52}$ Richard Wollheim, Painting as an Art, Princeton, 1987.

53 Wollheim, Painting as an Art, 8.

${ }^{54}$ Richard Wollheim, in Rob van Gerwen, ed., Richard Wollheim on the Art of Painting: Art as Representation and Expression, Cambridge, 2001, 260.

${ }^{55}$ For Cronan's comments on this aspect, see Against Affective Formalism, 105-6, 108.

${ }^{56}$ Compare the remarkably close comments by Alliez and Bonne on Matisse's 'matérialisme processuel' that does not separate ‘conception' off from 'réalisation'; La Pensée Matisse, 75-76. (A point itself there attributed by Alliez and Bonne to Yve-Alain Bois, 'Matisse and "Arche-drawing”, 28-29.)

${ }^{57}$ And although the appeal everywhere to written evidence and the activity of the agent 'Matisse' implies the above reading of affect, it is important to note here that the argument applies equally if a second, stronger, conception of affect is in play. It may be proposed that the affective charge of the picture-asobject simply is universal, and it has always impacted on everyone in the same way, whether they or we have been aware of it or not. In this case, however, Matisse is equally responsible as the final viewer of the picture-as-object before he relinquished work on it. The maker of the object is the one who was first 
hit by its particular affect, and (consciously) decided to send that affective object off into the world without further moderation.

${ }^{58}$ Yve-Alain Bois in conversation with Richard Brettell (2001), http://matisse-

picasso.org/conversations/matisse/ (accessed 20 February 2015).

${ }^{59}$ It is worth noting here that responses to this paper have ranged from the suggestion that it sets up a straw man because in reality everyone acknowledges the key role of intention, and that it sets up a straw man because in reality almost no one still thinks and writes as if intention plays an important role. I take the fact that both of these responses could be proposed by working art historians as a good justification for outlining these points about intention and description that have struck others as self-evident. I am especially grateful to Sophie Martin, Mike O’Mahoney, Simon Shaw-Miller, and the Art History reviewers for making this clear to me.

${ }^{60}$ Many examples and variations could be given here. For these three versions in particular, see Christopher Peacocke, 'The Perception of Music: Sources of Significance', British Journal of Aesthetics, 49, July 2009, 257-275; Davis, A General Theory of Visual Culture; Arthur Danto, 'Description and the Phenomenology of Painting', in Norman Bryson, Michael Ann Holly, and Keith Moxey, ed., Visual Theory: Painting and Interpretation, Cambridge, 1991.

${ }^{61}$ This owes greatly to Alexander Nehamas' brief but highly suggestive comments on the history of attempts to locate the particular 'aesthetic' properties of a work of art; Only a Promise of Happiness: The Place of Beauty in a World of Art, Princeton, 2007, 49-53.

${ }^{62}$ The process is explored below, but for a recent example of how such extremely complex looping can still return to an attenuated form of intention - in this case to Poussin's 'deepest thinking', his 'anthropology' - see T.J. Clark, 'Poussin's Sacrament of Marriage: An Interpretation', New Literary History, 45, Spring 2014, 221-252.

${ }^{63}$ Jennifer L. Roberts, 'The Power of Patience', Harvard Magazine, November-December 2013, http://harvardmagazine.com/2013/11/the-power-of-patience (accessed 10 December 2014). All quotations below are from this online source, which has no page numbers. The extended version of the argument is given in Jennifer Roberts, Transporting Visions: The Movement of Images in Early America, Berkeley, 2014, 4, 13-49.

${ }^{64}$ For a highly sophisticated recent example, see Marnin Young, 'Heroic Indolence: Realism and the Politics of Time in Raffaëlli’s “Absinthe Drinkers”, Art Bulletin, 90, June 2008, 235-259. 
${ }^{65}$ Michael Schreyach, 'Intention and Interpretation in Hans Namuth's Film, Jackson Pollock', Forum for Modern Language Studies, 48, October 2012, 449. All quotations in the subsequent paragraphs are from pages 446-449. For an extended analysis of the work, see Michael Schreyach, 'Pre-Objective Depth in Merleau-Ponty and Jackson Pollock', Research in Phenomenology, 43, 2013, 49-70.

${ }^{66}$ See Fried, 'Shape as Form: Frank Stella's Irregular Polygons', in Art and Objecthood, 77-99. The essay was originally published as 'Shape as Form: Frank Stella’s New Paintings', Artforum, 5, November 1966, 18-27.

${ }^{67}$ This is a contentious point, but is acknowledged by Fried for one, even if not by all of those he has influenced. For discussion of what Fried has called 'the ontological basis of modern art' as a governing context, see Robert Pippin, ‘Authenticity in Painting: Remarks on Michael Fried's Art History’, Critical Inquiry, 31, Spring 2005, 575-598. On the way that, as a result, intention is tied in to a notion of evolving 'convention', see Diarmuid Costello, 'On the Very Idea of a 'Specific' Medium: Stanley Cavell and Michael Fried on Painting and Photography as Arts', Critical Inquiry, 34, Winter 2008, especially 285295. I intend my notion of 'modernism as a context' to be broad enough to include its government of subsidiary contexts brought to bear on the work. Thus in Menzel's Realism Fried acknowledges the dialectic of context and description in his writing: 'The use of contextual material to set off or otherwise inform the description of individual works also means that the...distinction between ways of proceeding is far from absolute; in this book description and contextualization are two poles of a single dialectical operation that tacks continually back and forth between the close scrutiny of individual works and the establishing of force-fields of potential intelligibility, which sets the stage for further acts of intensive looking'; and later notes how the various contexts are all ones that centre on the issue of 'Menzel's modernity' - all 'have a place in any comprehensive consideration of the larger topic of modernity'; Fried, Menzel's Realism: Art and Embodiment in Nineteenth-Century Berlin, New Haven, 2002, 13, $252-$ 253.

${ }^{68}$ Rosalind Krauss, ‘A View of Modernism’ [first published in 1972], in Perpetual Inventory, Cambridge, Mass., 2010; Rosalind Krauss, 'Using Language to Do Business as Usual', in Visual Theory: Painting and Interpretation, ed., Norman Bryson, Michael Ann Holly, and Keith Moxey, London, 1991, 79-84; T.J. Clark, 'Clement Greenberg's Theory of Art' Critical Inquiry 9 (September 1982): 139-156; Michael Fried, 'How Modernism Works: A Reply to T.J. Clark' Critical Inquiry 9 (September 1982): 217-234. 
${ }^{69}$ See for example O.K. Werckmeister, 'A Critique of T.J. Clark's Farewell to an Idea', Critical Inquiry, 28, Summer 2002, 855-867; Andrew Hemingway and Paul Jaskot, 'Farewell to an Idea by T.J. Clark; Icons of the Left by Otto Karl Werckmeister', Historical Materialism, 7, 2000, 260-262; Jonathan Harris, Writing Back to Modern Art: After Greenberg, Fried, and Clark, New York, 2005; Richard Shiff, 'Breath of Modernism (Metonymic Drift)', in Terry Smith, ed., In Visible Touch: Modernism and Masculinity, Chicago, 1997, 184-213.

${ }^{70}$ Paraphrasing Cavell, Must We Mean What We Say?, 237.

${ }^{71}$ Quoted in David Plante, 'The Real Thing: An Interview with Rosalind E. Krauss', Artcritical, 30 August 2013, http://www.artcritical.com/2013/08/30/rosalind-krauss-interview/ (accessed 15 January 2015).

${ }^{72}$ This quotation is taken from Michael Fried, 'Sala with Schiller: World, Form, and Play in Mixed Behavior', Nonsite.org, 5, 18 March 2012. More generally see Michael Fried, Why Photography Matters as Art as Never Before, New Haven, 2008; Fried, Four Honest Outlaws.

${ }^{73}$ Rosalind Krauss, Under Blue Cup, Cambridge, Mass., 2011, 32. 